\title{
O DIREITO URBANÍSTICO E O PAPEL DA ATIVIDADE EMPRESARIAL NO DESENVOLVIMENTO DA CIDADE
}

Eduardo Felipe Veronese ${ }^{1}$

\section{RESUMO:}

O trabalho apresenta uma abordagem acerca da ótica solidarista da função social da empresa, que atribui a obrigação de além de prezar pela obtenção de lucro, atuar em defesa dos interesses da coletividade, para que a sua própria atividade empresarial seja sustentável. A partir do método dedutivo se buscou demonstrar que a atividade empresarial possui não apenas condição, mas também o dever de colaborar com a promoção dos direitos fundamentais no âmbito da cidade, atuando para complementar as ações implementadas pelo Poder Público, em muitos casos se valendo de incentivos públicos para a implementação e continuidade da atividade empresarial.

Palavras-chave: Direito urbanístico; desenvolvimento da cidade; direitos fundamentais; função social da empresa; políticas públicas.

\section{URBANISTIC LAW AND THE ROLE OF BUSINESS ACTIVITY IN THE DEVELOPMENT OF THE CITY}

\begin{abstract}
:
The work presents an approach about the solidarity perspective of the social function of the company, which attributes the obligation of not only valuing profit, acting in defense of the interests of the community, so that its own business activity is sustainable. The deductive method sought to demonstrate that business activity has not only conditions, but also the duty to collaborate with the promotion of fundamental rights within the city, acting to complement the actions implemented by the Government, in many cases using public incentives for the implementation and continuity of business activity.
\end{abstract}

keywords: Urbanistic law; development of the city; fundamental rights; social function of the company; public policy.

\section{INTRODUÇÃO}

Por não possuir condições de garantir diretamente a promoção dos direitos, compete ao Estado se valer de outras formas de cumprimento de seus objetivos, sendo um deles a participação da iniciativa privada na geração de emprego e renda, aumentando, por consequência, os recursos disponíveis ao Estado e, principalmente cumprindo uma função

\footnotetext{
${ }^{1}$ Mestre em Direito Empresarial e Cidadania na Faculdade de Direito do Centro Universitário Curitiba Unicuritiba. Especialista em Direito e Processo Civil na Faculdade de Direito do Centro Universitário Curitiba Unicuritiba. Especialista em Direito Administrativo pelo Instituto de Direito Romeu Felipe Bacellar. Bacharel em Direito pela Universidade Positivo - UP. eduardo@borgeseveronese.adv.br
} 
social capaz de integrar os indivíduos à cidade, garantir-lhes a liberdade por meio do acesso a direitos.

Para salvaguardar os direitos, a cidade precisa implementar políticas públicas, a partir de escolhas alocativas, para a satisfação dos interesses da sociedade. Entretanto, as ações afirmativas pelo Poder Público demandam recursos, que infelizmente são escassos, razão pela qual não se faz possível atender tudo e todos. Assim, sendo a atividade empresarial uma fonte de emprego e renda dentro do contexto da cidade, seria possível e viável a participação dela, em alguns casos até mesmo fazendo às vezes do Poder Público.

Para tanto, faz-se necessário abordar os objetivos e resultados da atividade, faz-se necessário abordar os objetivos e resultados da atividade empresarial, bem como os princípios norteadores e as consequências provenientes da sua observância, não apenas aos diretamente envolvidos, mas também aos sujeitos indiretamente afetados, ou seja, à sociedade como um todo, em razão da vinculação existente entre a empresa e o funcionamento da sociedade.

Em termos de problema a ser enfrentado, questiona-se: a atividade empresarial pode contribuir para o desenvolvimento econômico e social da cidade e para a efetivação da cidadania?

$\mathrm{Na}$ busca de soluções ao questionamento proposto, adotando o método dedutivo acerca do tema, analisar-se-á a temática empresarial sob o aspecto dogmático do direito civil e empresarial e, também, sob a ótica principiológica constitucional, examinando a constitucionalização do direito empresarial e, consequentemente, a função social das empresas, assim como as consequências sociais provenientes da sua atividade, voltando-se à efetivação dos direitos fundamentais.

Sendo assim, verificar-se-á, o papel da atividade empresarial no desenvolvimento da cidade, bem como os mecanismos legais disponíveis ao Poder Público para a concretização dos anseios sociais, promovendo a liberdade por meio do acesso a direitos fundamentais.

Por derradeiro, de forma dedutiva, pretende-se vincular o escopo da empresa na efetivação dos direitos fundamentais, a partir dos incentivos proporcionados pelo Poder Público, evidenciando a possibilidade de coexistência do cumprimento da função social da propriedade e do desenvolvimento da própria atividade, abordando o desenvolvimento econômico e social e, por fim, a apresentação de dados de desenvolvimento local, apresentando os resultados concretos, nesse sentido, de empresas que foram verdadeiramente responsáveis pelo desenvolvimento da cidade. 


\section{A FUNÇÃO SOCIAL DA CIDADE}

O direito urbanístico demanda uma abordagem a partir da distribuição constitucional de competências, constituindo-se em cerne para o desenvolvimento ordenado da cidade. Nesse sentido, rememore-se que aos municípios compete, conforme disposto no artigo 30 da Constituição, basicamente, legislar acerca de assuntos de interesse local, além de suplementar a legislação federal e estadual no que couber.

Atribui-se aos municípios, ainda, a partir da previsão constitucional, a promoção, no que couber, do adequado ordenamento territorial, por meio da realização de planejamento e controle do uso, do parcelamento e da ocupação do solo urbano, bem como da promoção da proteção do patrimônio histórico cultural do próprio município.

Dentro dessas atribuições conferidas pela Constituição, considerando ser ela a responsável pela integração de todas as normas inseridas no ordenamento jurídico, conformando o sistema, desenvolve-se o conceito de função social da cidade, em nítida superação à visão tradicional decorrente do modelo liberal de Estado, em que o Poder Público deveria atuar exclusivamente no cumprimento de suas funções típicas e essenciais.

Os artigos 182 e 183 da Constituição Federal estabeleceram a função social da cidade como premissa, mas conferiram ao plano diretor municipal a aplicação dos preceitos, competindo, então, a cada município a sua elaboração conforme o interesse local.

Atualmente, o modelo econômico adotado no Brasil direciona a uma identidade estatal afastada do liberalismo absoluto e também distante do extremo intervencionismo, prezando, em verdade, pelo atendimento às necessidades dos indivíduo. Para tanto, a cidade se apresenta como um centro de apoio à iniciativa privada, a fim de angariar recursos das mais diversas fontes por meio da atração de investimentos privados, sem, contudo, afastar-se dos interesses específicos dos habitantes do território. (SUNDFELD, 2009, p. 5)

Tem-se, então, que existe interesse público envolvido diretamente nas transações privadas, especialmente por estar nessas transações a principal fonte de arrecadação de recursos aos cofres públicos. Isso não significa, entretanto, que a propriedade privada deva sucumbir face ao interesse público e menos ainda a incidência do interesse público ser afastada para consagrar os ideais privados existentes nas relações. 
A consequência, em verdade, é a necessária adoção de procedimentos tendentes à otimização dos recursos disponíveis face às necessidades sociais que se apresentam em maior amplitude.

Para tanto, deve o Poder Público atuar não apenas com vias à satisfação dos direitos prestacionais, mediante a implementação de políticas públicas afirmativas, mas também por meio da garantia dos direitos de defesa, assegurando a evolução da atividade empresarial para o desenvolvimento econômico e social nas cidades e também impedindo que, com isso, eventualmente direitos dos indivíduos venham a ser suprimidos.

A Constituição brasileira de 1988 resguardou um plexo de autonomia sem similar na história brasileira, juntamente com a consideração do Município como ente partícipe do pacto federativo. Tal disposição encontra fundamento nos princípios basilares do federalismo, especialmente os princípios republicanos, não-concentração, Estado Democrático de Direito liberdade, democracia, pluralismo e subsidiariedade, além de encontrar sintonia com a própria organização federativa. (CORRALO, 2014, p. 244)

O espaço da cidade deve ser destinado às interações sociais, com vistas à promoção da igualdade material, possibilitando a todos os integrantes da sociedade os bens necessários à vida digna, tratando-se dos direitos sociais elencados no artigo $6^{\circ}$ da Constituição Federal.

Além de polissêmico, o direito à cidade não é expressamente assegurado por nenhum direito previsto no ordenamento jurídico. O que há é um conjunto de direitos que, uma vez interpretados sistematicamente, poderiam conduzir à sua fundamentação legal, sob a égide dos artigos 182 e 183 da Constituição Federal de 1988, que definem a política urbana e introduzem a ideia de "função social da cidade": o direito fundamental à propriedade e sua consequente hipoteca social (artigo $5^{\circ}$, caput, XXII e XXIII) e o rol de direitos sociais (artigo $6^{\circ}$, caput) que encontram na cidade o seu âmbito de materialização, sobretudo os direitos à educação, à saúde, à moradia, ao transporte, à segurança, ao lazer e à assistência aos desamparados, sem desprezar a normatividade infraconstitucional. (SILVA NETO, 2014, p. 126) 
Assim, a função social da cidade é tida como a orientação a ser seguida para vincular tanto o crescimento e o desenvolvimento econômico, como também garantir aos indivíduos o acesso aos direitos que lhes são conferidos pelas previsões da Constituição.

Atualmente, o princípio da função social da cidade tem sido entendido como um desdobramento do princípio da função social da propriedade. Isto, pois, a corrente neoliberal foi responsável por difundir influências das mais diversas ordens, inclusive em relação ao direito urbanístico, modernizando as necessidades municipais e atraindo maiores investimentos e melhor infraestrutura aos indivíduos. (SALEME, 2009, p. 10)

\section{A ORGANIZAÇÃO DA CIDADE E O INCENTIVO À ATIVIDADE EMPRESARIAL}

Para regulamentar as normas constitucionais atinentes aos municípios, especialmente os artigos 182 e 183, foi editado o Estatuto das Cidades (Lei n ${ }^{\circ} 10.257 / 2001$ ), correspondendo ao ápice do tratamento jurídico despendido à cidade no ordenamento jurídico, tendo em vista que contempla as diretrizes e fundamentos do planejamento urbano, fixando direitos e deveres não apenas aos munícipes, mas também aos gestores.

Por meio dessa lei, objetiva-se estabelecer normas de ordem pública e interesse social com vistas a regular o uso da propriedade urbana em benefício da coletividade, do bemestar dos indivíduos, da segurança e do equilíbrio ambiental, tendo entre as suas premissas o direito ao trabalho, ao lazer, ao transporte, aos serviços públicos e à moradia.

Tratando-se de direito difuso, seu objetivo está vinculado ao desenvolvimento urbano, de modo que a sua realização ocorre mediante a construção de cidades mais justas, humanas e democráticas, que possibilitem condições dignas de vida para o exercício dos direitos individuais e coletivos. (CANUTO, 2008, p. 110)

O Estatuto das Cidades, então, materializa o conceito de função social da cidade, pois estabelece normas de ordem pública e interesse social, viabilizando a realização de política urbana pautada na participação social e no pleno desenvolvimento. (DALLARI, 2007, p. 57)

O Estatuto da Cidade evidencia (...) a importância da gestão democrática municipal como um mecanismo implementador do princípio da dignidade humana. Diante da 
constatação da situação de desequilíbrio vivenciada na grande maioria das cidades, em que grande parte dos habitantes permanece à margem da infra-estrutura e dos serviços públicos municipais (gerando conceitos como cidade formal - incluídos - e cidade informal - excluídos), a gestão democrática municipal mostra-se um importante instrumento nas mãos da cidadania a fim de reverter este estado de coisas, a partir de sua participação na aprovação coletiva dos projetos para a cidade. Pleiteia-se, com essa nova política urbana, o direito de cada cidadão em participar do planejamento a respeito do desenvolvimento da cidade, garantindo que ela seja sustentável para esta e para as futuras gerações. (SANTIN; MARAGON, 2008, p. 38)

Essa lei é inovadora em diversos aspectos. Primeiro, evidencia a existência de uma construção desigual na sociedade, bem como reconhece o predomínio da população urbana e a falta de acesso por diversos integrantes da sociedade a padrões mínimos de urbanidade. Depois, esclarece que a cidade é um produto coletivo e que a população urbana não é a causa dos problemas, mas que esses problemas sociais precisam ser analisados a partir da complexidade da produção.

Ainda, a cidadania fica mais evidente a partir do Estatuto da Cidade, que forneceu subsídios à gestão democrática das cidades por mecanismos diversos, como ação de conselhos de política urbana, leis de iniciativa popular, debates, consultas e audiências públicas para a implementação dos planos diretores e leis orçamentárias municipais.

No capítulo II do Estatuto da Cidade, especialmente no artigo $4^{\circ}$, restam fixados os instrumentos da política urbana que deverão ser utilizados para o cumprimento dos objetivos não apenas previstos na própria lei, mas principalmente na Constituição Federal.

Dentre os mecanismos, está o Plano Diretor, obrigatório para municípios com mais de 20 mil habitantes, integrantes de regiões metropolitanas e aglomerações urbanas e de áreas de interesse turístico.

o plano diretor é o mais importante instrumento de planificação urbana previsto no Direito Brasileiro, sendo obrigatório para alguns Municípios e facultativo para outros; deve ser aprovado por lei e tem, entre outras prerrogativas, a condição de definir qual a função social a ser atingida pela propriedade urbana e de viabilizar a adoção dos demais instrumentos de implementação da política urbana (DALLARI; FERRAZ, 2006, p. 324). 
O Plano Diretor corresponde ao instrumento da política de desenvolvimento do Município. Sua finalidade precípua é fornecer orientação ao Poder Público e também à iniciativa privada para o desenvolvimento e urbanização da cidade para a construção e utilização dos espaços urbanos e rurais na oferta dos serviços públicos essenciais. Com isso, pretende-se garantir melhores condições de vida para a população no âmbito municipal.

Nesse aspecto, entende-se que

será o plano diretor o instrumento jurídico competente para precisar a fluidez do conceito de função social da propriedade urbana. Fez isso ao afirmar que 'a propriedade urbana cumpre sua função social quando atende às exigências fundamentais de ordenação da cidade expressas no plano diretor. (CÂMARA, 2006, p. 323).

Ou seja, refere-se a uma lei municipal específica, que tem por objeto o planejamento para o desenvolvimento da cidade, que deverá ocorrer por meio de ações afirmativas por parte do Poder Público e empreendimento por parte da iniciativa privada.

Em suma, o Plano Diretor é uma lei municipal que estabelece diretrizes para a adequada ocupação do município, determinando o que pode e o que não pode ser feito em cada parte do mesmo e que deve obedecer às diretrizes do Estatuto da Cidade, dentre eles a segurança.

O plano diretor corresponde ao complexo de normas legais e diretrizes técnicas, voltadas ao desenvolvimento do município, nos aspectos físico, social, econômico e administrativo, a partir dos anseios da comunidade local. Assim, deve esse plano refletir as vontades dos indivíduos, a fim de orientar a administração pública. (MEIRELLES, 2008, p. $550)$

Não apenas os objetivos gerais são incluídos no plano diretor, mas também os objetivos específicos e concretos, direcionados à realidade de cada município, tendo em seu conteúdo o aspecto físico de ordenação do solo, envolvendo o zoneamento urbano, o aspecto social, referente aos serviços a serem disponibilizados à população, e o aspecto administrativo institucional, direcionando os meios de execução do plano. (SILVA, 2010, p. 139)

O Estatuto da Cidade estabelece que o Plano Diretor deve ser elaborado a partir das suas premissas básicas, estabelecendo, por consequência, regras sobre o planejamento urbano, por exemplo, o art. 25 trata do direito de preempção, o art. 28 do coeficiente de 
aproveitamento básico que pode ser diferente em certas áreas fixadas, o art. 29 sobre áreas de alteração de uso do solo mediante contraprestação do beneficiário, o art. 32 sobre delimitação de área para aplicação de operação consorciada, o art. 35 de autorização de exercer em outro lugar ou alienar o direito de construir caso o imóvel seja considerado como necessário para a sociedade e justiça social, enquanto o art. $42, \S 2^{\circ}$, diz que se o município apresentar mais de 500 mil habitantes, deve existir, compatível com o plano diretor, um plano de transporte urbano integrado.

A partir dessa análise, tem-se que o Estatuto da Cidade, em conjunto com o Plano Diretor, direciona até mesmo o funcionamento da atividade empresarial, estabelecendo os limites ao seu exercício, nos termos da lei, sempre direcionando-a à satisfação dos interesses da coletividade.

Nesse sentido, é possível destacar o contido no artigo $2^{\circ}$, XIII, do Estatuto da Cidade, em relação à implantação de empreendimentos e atividades com efeitos possivelmente nocivos ao meio ambiente:

Art. $2^{\mathrm{o}}$ A política urbana tem por objetivo ordenar o pleno desenvolvimento das funções sociais da cidade e da propriedade urbana, mediante as seguintes diretrizes gerais: (...)

XIII - audiência do Poder Público municipal e da população interessada nos processos de implantação de empreendimentos ou atividades com efeitos potencialmente negativos sobre o meio ambiente natural ou construído, o conforto ou a segurança da população;

Nota-se, portanto, que o Plano Diretor exerce influência direta em relação à atividade empresarial e seus reflexos no contexto da cidade, inclinando-se sempre ao benefício coletivo, ao atendimento dos anseios da população no que tange ao desenvolvimento. Com isso, pode haver a limitação, o impedimento ao exercício de atividade empresarial no âmbito da cidade, como também pode ocorrer a atuação do Poder Público no sentido de auxiliar a iniciativa privada a implementar atividade que seja capaz de contribuir para o desenvolvimento.

Importante esclarecer que, em razão de dispositivos constitucionais, por exemplo os artigos 70, 74, II, e 174 da Constituição, e legais, por exemplo o artigo 17 da Lei nº 8.666/93 e o artigo $7^{\circ}$ do Decreto-lei $n^{\circ} 271 / 67$, é possível a concessão de benefícios econômicos para empresas de fins lucrativos, a fim de que acabem por se instalar naquela unidade federativa. 
Esses benefícios que podem ser concedidos à iniciativa privada estão diretamente vinculados às leis municipais que estabelecem as diretrizes para o desenvolvimento no âmbito da cidade, de modo que o direito urbanístico, em verdade, possui significativa influência nos resultados dos processos sociais.

Por isso, apesar de ser admitido no ordenamento jurídico a concessão de benefícios à iniciativa privada em situações previamente estabelecidas na legislação, por regras ou princípios, não se admite a ocorrência desses procedimentos sem que, para tanto, tenha ocorrido autorização anterior.

Contudo, estes incentivos, como quaisquer atos da Administração Pública, estão sujeitos à observância de uma série de princípios, pois eles formam os mandamentos nucleares do nosso ordenamento jurídico. Dentre estes princípios destacamos os de ordem constitucional: legalidade, impessoalidade, moralidade, publicidade e eficiência; da supremacia do interesse público; da obrigatoriedade de licitação; da igualdade e da economicidade; e outros decorrentes do próprio ordenamento jurídico: finalidade, proporcionalidade, razoabilidade, motivação. Assim, não se pode perder de vista que, embora permitidos, os incentivos à empresas privadas de fins lucrativos devem respeitar os princípios que regem a Administração Pública e os requisitos previstos pela legislação, sob pena de invalidade do ato de concessão e de responsabilização do agente público responsável. (SCHIRMER; BERTONCINI, 2012, p. 3)

Conforme anteriormente exposto, os princípios inseridos na Constituição Federal devem ser analisados sempre a partir da ideia de sistema, interligando-os às demais normas, em forma de complementação e unificação, não podendo de forma alguma ocorrer a interpretação isolada. Nesse aspecto também a atenção aos princípios constitucionais direciona a atividade empresarial à observância do direito urbanístico, tendo em vista o seu caráter complementar, mas essencial.

Ante ao exposto, a Constituição Federal, em seu artigo 150, $\S 6^{\circ}$, define a necessidade de qualquer subsídio ou isenção estar amparado em lei específica, a fim de que seja mantida a organização na administração, tratando-se de desdobramento do princípio da legalidade: 
Art. 150. Sem prejuízo de outras garantias asseguradas ao contribuinte, é vedado à União, aos Estados, ao Distrito Federal e aos Municípios: (...)

§ 6. ${ }^{\circ}$ Qualquer subsídio ou isenção, redução de base de cálculo, concessão de crédito presumido, anistia ou remissão, relativos a impostos, taxas ou contribuições, só poderá ser concedido mediante lei específica, federal, estadual ou municipal, que regule exclusivamente as matérias acima enumeradas ou o correspondente tributo ou contribuição, sem prejuízo do disposto no art. $155, \S 2 .^{\circ}, \mathrm{XII}, \mathrm{g}$.

Mais uma vez, tem-se que eventual política pública a ser implementada no âmbito da cidade obrigatoriamente precisa estar amparada em lei, sendo que quando envolver movimentações financeiras, obrigatoriamente deve ser prevista não apenas no plano diretor, mas principalmente nas leis orçamentárias, que previamente fixam as receitas e despesas daquele ente federativo.

Assim, as despesas com incentivos e também as renúncias tributárias, que influenciam diretamente na receita, obrigatoriamente devem ser previstas no orçamento, nos termos do artigo 165 da Constituição Federal:

Art. 165. Leis de iniciativa do Poder Executivo estabelecerão: (...)

$\S 2^{\circ}$ A lei de diretrizes orçamentárias compreenderá as metas e prioridades da administração pública federal, incluindo as despesas de capital para o exercício financeiro subseqüente, orientará a elaboração da lei orçamentária anual, disporá sobre as alterações na legislação tributária e estabelecerá a política de aplicação das agências financeiras oficiais de fomento. (...)

$\S 6^{\circ}$ O projeto de lei orçamentária será acompanhado de demonstrativo regionalizado do efeito, sobre as receitas e despesas, decorrente de isenções, anistias, remissões, subsídios e benefícios de natureza financeira, tributária e creditícia.

$\mathrm{Na}$ análise da referida previsão legal, ao abordar a aplicação ao contexto da cidade, conclui-se que há obrigatoriedade, para a implementação das políticas públicas mencionadas, de previsão orçamentária e prévia inclusão nas leis municipais, quais sejam, o Plano Plurianual, a Lei de Diretrizes Orçamentárias e a Lei Orçamentária Anual, vinculando-se, portanto, a um completo arcabouço jurídico vinculado à questão urbanística.

A partir da forma de organização da cidade, com todo o seu complexo núcleo normativo, constata-se não apenas a possibilidade, mas a necessidade de haver planejamento por parte do Poder Público para que ocorra a implementação e continuidade da atividade 
empresarial, havendo, inclusive, mecanismos para, não apenas regulamentar a atuação da iniciativa privada, mas também incentiva-la a integrar o contexto da cidade e, dentro do seu objetivo precípuo, que é a obtenção de lucro, também cumprir a sua função social.

\section{O DESENVOLVIMENTO ECONÔMICO E SUA FUNÇÃO PARA A PROMOÇÃO DOS DIREITOS FUNDAMENTAIS}

Constatada a possibilidade de atuação do Poder Público em favor da implementação e continuidade da atividade empresarial, com vistas ao desenvolvimento da cidade e, por conseguinte, melhora das condições de vida dos habitantes, passa-se à verificação das razões para a ocorrência dessa autorização legal.

A possibilidade de atuação do município no campo econômico já foi objeto de análise pelo Supremo Tribunal Federal, na ADIn $n^{\circ}$ 1.950/SP, de relatoria do ministro Eros Grau, restando consignado na decisão o seguinte texto:

\footnotetext{
Afasto desde logo a alegação de inconstitucionalidade formal. Bem ao contrário do que sustenta a requerente, não apenas a União pode atuar sobre o domínio econômico, isto é, na linguagem corrente, intervir na economia. Não somente a União, mas também os Estados- -membros e o Distrito Federal, nos termos do disposto no artigo 24, inciso I, da Constituição do Brasil, detêm competência concorrente para legislar sobre direito econômico. Também podem fazê-lo os Municípios, que, além de disporem normas de ordem pública que alcançam o exercício da atividade econômica, legislam sobre assuntos de interesse local, aí abrangidos os atinentes à sua economia, na forma do artigo 30, inciso I, da CB/88.
}

Conforme anteriormente exposto, os princípios constitucionais são pilares para a conformação do ordenamento jurídico. Todas as normas existentes precisam estar em consonância com a gama de princípios que norteiam a atuação do legislador e, consequentemente, também do gestor público.

Tendo em vista que a cidade, em decorrência da sua função social, precisa ser feita pelos seus integrantes e para os seus integrantes, o resultado é que as ações a serem implementadas pelo Poder Público devem ocorrer guiadas pelo objetivo comum, pela intenção de beneficiar a coletividade, não apenas um grupo restrito, vinculando-as, portanto, ao interesse público. 
No Estado Social de Direito não apenas o Estado ampliou suas atividades e funções, mas também a sociedade cada vez mais participa ativamente do exercício do poder, de tal sorte que a liberdade individual não apenas carece de proteção contra os poderes públicos, mas também contra os mais fortes no âmbito da sociedade, isto é, os detentores de poder social e econômico, já que é nesta esfera que as liberdades se encontram particularmente ameaçadas (SARLET, 2006, p. 395)

Assim, o interesse público é a finalidade da tutela do Estado, o ponto central para o exercício das atividades no contexto da cidade, tanto pela iniciativa privada como pelo Poder Público, objetivando proporcionar condições de vida digna aos integrantes da sociedade.

Por essa razão, além da necessária observância à legislação vigente, tem-se que os incentivos econômicos à empresas privadas de fins lucrativos só podem ser
concedidos para atender o interesse público, interesse geral de toda sociedade, razão
pela qual não podem ser concedidos graciosamente, devendo existir uma
contraprestação por parte dos beneficiários, expressa em lei ou contrato, com
garantias concretas de sua execução. (SCHIRMER; BERTONCINI, 2012, p. 12)

O objetivo a ser perseguido pelo Estado em todas as suas áreas de atuação, inclusive na seara econômica, passa a ser o humano, em todas as dimensões, com uma estrutura voltada para o bem-estar e desenvolvimento do mesmo, colocando-o como centro do universo jurídico-constitucional. Assim, reconhece-se que um dos fins do Estado é proporcionar as condições mínimas para que as pessoas tenham dignidade. (HOLANDA, 2014, p. 68)

O desenvolvimento econômico envolve uma série de variáveis de ordem qualitativa e quantitativa, que conduzem a uma radical mudança de estrutura da economia e da própria sociedade, mudanças inclusive de ordem psicológica, cultura e política. Neste sentido, o progresso resultante do desenvolvimento econômico proporciona alterações estruturais, haja vista que a sua estrutura passa por modificações substanciais que o levam ao novo status. É possível identificar alguns fatores do processo de desenvolvimento de um país, como a quebra do círculo vicioso da pobreza, que é o desafio inicial de qualquer política de desenvolvimento e progresso tecnológico. (GRAU, 2008, p. 60)

O Estado é uma realidade instrumental, que deve primar pela busca da plena efetividade, a plena concretização dos princípios, dos objetivos e dos direitos fundamentais. 
Por essa razão, a atuação do Estado deve ocorrer de modo sincronizado, administrando, legislando e julgando, todos com um objetivo, qual seja, a busca da plena satisfação dos direitos fundamentais. Caso o Estado venha a se desviar desse fundamento, estará ele, do ponto de vista político, se deslegitimando, e do ponto de vista jurídico, se desconstitucionalizando. (CLÈVE, 2003, p. 388)

Para o cumprimento dessas obrigações, em decorrência dos princípios do Estado de Social Democracia implementado no Brasil, o Estado não mais se limita a exercer a fiscalização das atividades desempenhadas pelos particulares, tendo convocado para si uma série de tarefas que não se esgotam pela pura aplicação da lei ao caso concreto, mas vão além para alargar as competências da atividade estatal, possibilitando-lhe a atuação diretamente no campo econômico, por diversos mecanismos, por exemplo, o fomento. (CLÈVE, 2003, p. 389)

O fomento pode ser entendido como um mecanismo administrativo de extrema relevância, possuindo característica de regime jurídico-administrativo, relacionado ao estímulo, impulso ou auxílio, capaz de proporcionar um impacto muito positivo à sociedade.

Esse mecanismo corresponde à atividade promovedora do desenvolvimento social, objetivando superar diversas demandas da sociedade, decorrentes da redemocratização brasileira, mediante repasse aos particulares de recursos a serem aplicados a fins sociais. (MELLO, 2016, p. 504)

A Constituição Federal define que o Estado é o responsável pela concretização dos direitos sociais, sendo que, pela corrente conservadora e social, poderá promover a atividade de fomento por meio de contribuições, auxílios e subvenções, traduzindo-se no formato que se considera como fomento direto. (ROCHA, 2003 p. 32)

Entretanto, a corrente neoliberal, tendo como expoentes Diogo de Figueiredo Moreira Neto e Maria Sylvia Zanella Di Pietro, entende que o Estado possui por obrigação o incentivo à produção de capital e desenvolvimento social, sendo-lhe facultado proporcionar condições de progresso mediante a utilização da ferramenta do fomento.

Dentre as modalidades de fomento disponíveis ao Estado para aplicação em favor da iniciativa privada estão os meios honoríficos, quais sejam, prêmios, recompensas, títulos e menções honrosas, os meios jurídicos, que correspondem à outorga de privilégios próprios do Poder Público e não disponíveis a outras entidades, além dos meios econômicos, que 
contemplam os auxílios, as subvenções, os financiamentos, as isenções fiscais e as desapropriações por interesse social. (DI PIETRO, 2006, p. 21)

Nesse sentido, a função administrativa desempenhada pelo fomento está direcionada à proteção e promoção do objeto ao qual se vincula, não se tratando, para tanto, de medida compulsória, com vistas à satisfação indireta do arcabouço de necessidades da coletividade, sendo possível a concessão de vantagens ou incentivos àqueles que colaborarem com a Administração Pública, tanto particulares quanto outros entes públicos (MELLO, 2003, p. 198)

Incentivos fiscais são renúncias de receitas públicas que beneficiam os contribuintes, baseados em instrumentos de desoneração tributária, onde o Estado dispensa um tratamento tributário diferenciado ao contribuinte, com objetivo de promover o desenvolvimento econômico regional; reduzir as desigualdades sociais nacionais e regionais; gerar empregos ou fomentar setores econômicos específicos. Neste contexto, a renúncia fiscal é a forma pela qual o Estado utiliza os tributos para alcançar outros fins que não o de arrecadação, como, por exemplo, incentivar certas atividades ou regiões. (FORMIGONI, 2008, p. 96)

Ressalte-se que os incentivos fiscais não visam o privilégio do contribuinte, mas promover ações ou comportamentos em prol da sociedade. Fazem parte desse gênero: as isenções, as reduções de alíquota e de base de cálculo, a alíquota zero, as subvenções, os créditos presumidos, os subsídios e o diferimento. Assim, uma norma jurídica que não exija contrapartida vinculada à promoção do bem comum não institui incentivo fiscal, mas, sim, benefício fiscal, gerando privilégio diretamente dirigido ao contribuinte, o que afronta que prevê o ordenamento jurídico pátrio, não podendo ser implementado.

Fato é que, além da obrigação do Estado promover de forma direta o acesso a direitos fundamentais, na medida de suas possibilidades, compete a ele, quando exauridas as condições de atuação e ainda existentes as demandas sociais, induzir a atividade empresarial a concretizar o desenvolvimento econômico e, em sequência, social.

Considerando a necessidade de complementação das ações que visem à promoção de direitos fundamentais, a função social da empresa é alçada à qualidade de solução ao menos para reduzir as desigualdades geradas pelas complexas relações sociais e também para promover o acesso a direitos no contexto da cidade e proporcionar liberdade a partir do desenvolvimento. 
No caso das concessões de benefícios para empresas privadas de fins lucrativos instalarem-se em determinada unidade da federação, vislumbra-se os seguintes interesses: a) o interesse do empresário; b) aumento de receitas públicas; c) aumento da oferta de empregos. O interesse da empresa em receber os incentivos é, imediatamente, um interesse particular, caracterizado na diminuição de custos e no conseqüente aumento dos lucros do empresário, de modo que não sendo um interesse geral não se coaduna com o interesse público. O interesse consistente no aumento de arrecadação depois de expirado o prazo da isenção pode ser considerado de natureza pública, pois o aumento da receita importará em benefício da sociedade como um todo, pois o Estado terá recursos para proporcionar a sua finalidade, o bem comum. O interesse na geração de empregos pode ser considerado interesse público, na medida em que o emprego é uma das maiores preocupações atuais, devendo o Estado empenhar-se em resolvê-lo. (SCHIRMER; BERTONCINI, 2012, p. 12)

Entretanto, pelo que restou anteriormente constado, os recursos públicos são limitados, não havendo disponibilidade para que o Poder Público, a todo momento e de forma indiscriminada, promova incentivos à implementação e manutenção da atividade empresarial, devendo essas políticas públicas serem submetidas à minuciosa análise prévia.

Isso, pois,

o interesse público exige proporcionalidade, razoabilidade e economicidade, razão pela qual em cada caso concreto deve ser analisada a relação custo/benefício entre os incentivos oferecidos aos beneficiários e as contraprestações de interesse público que estes devem proporcionar, fatores que vão demonstrar a existência ou não de interesse público. (SCHIRMER; BERTONCINI, 2012, p. 14)

O desenvolvimento deve estar relacionado sobretudo com a melhora da qualidade de vida conferida aos indivíduos e das liberdades de que desfrutam. O indivíduo é o sujeito principal no processo de desenvolvimento, superando a análise sob a ótica preponderante do crescimento econômico, ou seja, do direito do desenvolvimento. O indivíduo é capacitado a interagir, a partir dos seus anseios e conforme a sua satisfação, para influenciar o contexto social em que está inserido.

Trata-se de uma via de mão dupla, pois ao mesmo tempo em que o atendimento à função social da cidade direciona as ações do Poder Público a proporcionar incentivos à atividade empresarial, gerando, por consequência, aumento de riquezas, a empresa precisa, 
obrigatoriamente, observar sua função social, transferindo não apenas aos seus colaboradores, mas também à sociedade como um todo, um auxílio ao desenvolvimento, principalmente pela geração de renda, conferindo liberdade aos indivíduos.

Portanto, o desenvolvimento econômico, que resulta no aumento de riquezas, por meio da atividade empresarial significa maior geração de emprego e renda à população. Ainda, a partir do desenvolvimento da cidade, especialmente pelo cumprimento da função social da empresa, o acesso a direitos fundamentais resta facilitado, uma vez que o Poder Público não possui condições de promove-los integralmente por si só, demandando o auxílio de outro meio de produção.

A facilitação do acesso a direitos no âmbito da cidade em decorrência do desenvolvimento, movido especialmente pela atividade empresarial, é capaz de promover, ao menos em parte, a liberdade aos indivíduos em decorrência da qualidade de vida e da possibilidade de vive-la como melhor lhe aprouver, sem, para tanto, ser submetido a situações para a garantia da subsistência.

\section{CONSIDERAÇÕES FINAIS}

No Brasil, apesar da existência de codificações infraconstitucionais que possuem por escopo o regramento das atividades empresariais, nesse sentido englobada a relação com fornecedores, colaboradores, consumidores e afins, a Constituição de 1988 impõe a todo o ordenamento jurídico a observância de uma série de princípios.

Esses princípios, aplicáveis a todas as codificações, exigem que todo regramento seja pautado na tentativa de efetivar os direitos consagrados na Constituição, tanto os chamados de primeira dimensão como também os de segunda e terceira dimensão, de modo que o bem estar social seja alcançado. Ocorre, portanto, a chamada constitucionalização do direito, nesse caso o direito empresarial, de modo que apesar de existir a separação semântica, não há autonomia entre os diversos ramos do direito, tratando-se antes de uma unidade sistêmica.

Nesse contexto, a atividade empresarial assume extrema relevância social, pois contribui decisivamente para o funcionamento da vida social, na medida em que responsável por produzir riquezas, distribuir renda e possibilitar a arrecadação de impostos.

Por essa razão, a empresa não pode se furtar às obrigações da função social, em especial da implementação de ações para a efetivação dos direitos individuais e coletivos, 
tendo em vista que, em verdade, é apenas com medidas nesse sentido que será possível a maximização de lucros.

No atual quadro de evolução social da sociedade brasileira, o arranjo na gestão da atividade empresarial, comprometida com a competitividade e a maximização do lucro não pode negligenciar as finalidades de funcionalização ligadas à efetivação dos direitos fundamentais. Dito de outro modo, o arcabouço da ordem econômica constitucional estabelece uma relação de complementaridade funcional entre os propósitos de competitividade e de maximização do lucro e as obrigações decorrentes da função social da atividade empresarial. A compreensão dessa relação por administradores e empresários é fundamental para o sucesso da atividade empresarial enquanto integrante da cidade.

Considerando-se todas as peculiaridades que envolvem a atividade empresarial, é possível afirmar que a superação da liberdade irrestrita de atuar submete a autonomia da vontade ao exercício em razão e nos limites impostos pelo ordenamento jurídico, em especial, nesse sentido, da função social da empresa, impondo-se, assim, a atuação nos limites estabelecidos pela Constituição Federal, especialmente pelo disposto no artigo 170.

No contexto da cidade, resta inegável a inexistência de recursos suficientes à disposição do Poder Público para a garantia dos direitos prestacionais. A realização de políticas públicas demanda investimento, que o Estado, por si só, não sendo ele diretamente o gerador de riquezas, não possui de forma ilimitada.

A necessidade da realização de escolhas alocativas limita consideravelmente o campo de atuação do Poder Público, que a partir de uma análise econômica precisa atuar no sentido de beneficiar a maior quantidade possível de pessoas com os escassos recursos de que dispõe.

Por consequência, faz-se necessário implementar ações que estimulem a implementação e a manutenção da atividade empresarial, para que ela tenha condições de potencializar sua produção e contribuir para o desenvolvimento.

O desenvolvimento das atividades empresariais por meio do incentivo proporcionado no âmbito da cidade, resulta em maior distribuição de renda por meio da criação de postos de trabalho, gerando, também, maior liberdade aos indivíduos, que conseguem se afastar da submissão face à necessidade de subsistência e passam a ter de fato valorizada a sua força de trabalho. 
Com a geração de renda, o acesso direto, sem a necessidade de intervenção do Estado, acaba sendo facilitado e os direitos fundamentais constitucionalmente assegurados são com maior facilidade implementados no contexto social, satisfazendo os anseios da população e conformando a organização do Estado e seus elementos constitutivos.

Sendo assim, em resposta ao problema que culminou no desenvolvimento da presente pesquisa, é possível afirmar que a atividade empresarial possui grande potencial para contribuir para o desenvolvimento econômico e social da cidade e, por consequência, promover o acesso a direitos fundamentais e liberdades, efetivando a cidadania.

Entretanto, para que haja maior investimento na atividade empresarial, a fim de possibilitar o desenvolvimento e facilitar o acesso dos indivíduos aos direitos constitucionalmente previstos, há necessidade do Estado, dentro dos limites legais e observados os princípios constitucionais, conceder incentivos que resultem na geração de emprego e renda, distribuindo riquezas, especialmente se analisado pelo contexto da cidade.

\section{REFERÊNCIAS}

CÂMARA, Jacintho Arruda et. al. Estatuto da Cidade: Comentário à Lei Federal 10.257/2001. 3. ed. São Paulo: Malheiros, 2006.

CANUTO, Elza Maria Alves. O direito à moradia urbana como um dos pressupostos para a efetivação da dignidade da pessoa humana. 2008. Tese (Doutorado em geografia) Universidade Federal de Uberlândia, Minas Gerais, 2008.

CLÈVE, Clèmerson Merlin. O controle da constitucionalidade e a efetividade dos direitos fundamentais. In: SAMPAIO, José Adércio Leite (Coord.). Jurisdição constitucional e direitos fundamentais. Belo Horizonte: Del Rey, 2003. p. 385-393.

CORRALO, Giovani da Silva. Município: autonomia na Federação Brasileira. Curitiba: Juruá, 2014.

DALLARI, Adilson Abreu. Direito urbanístico ambiental. Belo Horizonte: Fórum, 2007.

DALLARI, Adilson Abreu; FERRAZ, Sérgio. Estatuto da cidade: Comentários à lei federal 10.257/2001. 2. ed. São Paulo: Malheiros, 2006.

DI PIETRO, Maria Sylvia Zanella. Parcerias na administração pública: concessão, permissão, franquia, terceirização e outras formas. 5. ed. São Paulo: Atlas, 2006.

FORMIGONI, Henrique. A influência dos incentivos fiscais sobre a estrutura de capital e a rentabilidade das companhias abertas brasileiras não financeiras. 2008. Tese 
(Doutorado em Controladoria e Contabilidade: Contabilidade) - Faculdade de Economia, Administração e Contabilidade, Universidade de São Paulo, São Paulo, 2008.

GRAU, Eros. A ordem econômica na Constituição de 1988. 13. ed. São Paulo: Malheiros, 2008.

HOLANDA, Marcus Mauricius. Análise constitucional do acesso ao trabalho digno, como instrumento do desenvolvimento econômico e social. Rio de Janeiro: Lumen Juris, 2014.

MEIRELLES, Hely Lopes. Direito municipal brasileiro. São Paulo: Malheiros, 2008.

MELLO, Célia Cunha. O fomento da administração pública. Belo Horizonte: Del Rey, 2003.

MELlO, Celso Antônio Bandeira de. Curso de Direito Administrativo. 28. ed. São Paulo: Malheiros, 2016.

ROCHA, Sílvio Luís Ferreira da. Terceiro setor. São Paulo: Malheiros, 2003.

SALEME, Edson Ricardo. Parâmetros sobre a função social da cidade. Disponível em: < http://www.publicadireito.com.br/conpedi/manaus/arquivos/anais/XIVCongresso/141.pdf >. Acesso em: 10.mar.2020.

SANTIN, Janaína Rigo; MARAGON, Elizete Gonçalves. O estatuto da cidade e os instrumentos de política urbana para proteção do patrimônio histórico: outorga onerosa e transferência de direito de construir. Disponível em: $<$ http://www.scielo.br/scielo.php?pid=S0101-

90742008000200006\&script=sci_abstract\&tlng=pt $>$. Acesso em 06.mar.2020.

SARLET, Ingo Wolfgang. A eficácia dos direitos fundamentais. 6 ed. Porto Alegre: Livraria do Advogado, 2006.

SCHIRMER, Mário Sérgio de Albuquerque; BERTONCINI, Mateus Eduardo Siqueira Nunes. Da concessão de benefícios econômicos pelo poder público à empresa privada, como incentivo à industrialização. Disponível em: <http://www.patrimoniopublico.mppr.mp.br/arquivos/File/Artigos_Testes_Estudos/Tese_ince ntivo_empresas.pdf >. Acesso em: 05.mar.2020.

SILVA, José Afonso da. Direito urbanístico brasileiro. São Paulo: Malheiros, 2010.

SILVA NETO, Wilson Levy Braga da. O direito urbanístico em discussão: as zonas especiais de interesse social. Revista de direito da cidade, Brasília, v. 6, 2014.

SUNDFELD, Carlos Ary. Função social da propriedade. In: Temas de direito urbanístico, coordenado por Adilson de Abreu Dallari. São Paulo: Revista dos Tribunais, 2009. 